\title{
Chemotherapy and Oral Health in Leukemic Patients
}

\section{Maja Ptasiewicz*, Agnieszka Katarzyna Pawłowicz, Barbara Tymczyna-Borowicz}

\author{
Chair and Department of Conservative Dentistry with Endodontics, Medical University of Lublin, Poland
}

Received: 6 September 2019

Accepted: 14 November 2019

\begin{abstract}
Leukemias are neoplastic diseases originating from the hematopoietic system and may be generally divided into acute and chronic forms. Dental treatment of patients with leukemia should be planned on the basis of antineoplastic therapy, which can be chemotherapy with or without radiotherapy and bone marrow transplantation. This is an orginal study with a sample of 102 adolescents evaluated before and after chemotherapy. Within oral mucosa of the examined patients ulcerations and gingival hyperplasia were the most frequently observed. These are typical disorders of the oral mucosa that occur in leukemia. The decrease in the number of red blood cells and hemoglobin predisposes to pathological changes within the oral mucosa. Pathological changes within the oral mucosa were also observed more often in patients after chemotherapy who had decreased immunity assessed on the basis of a white blood cell count. It is concluded in this paper that dental treatment in relation to hematological indices presented by patients with leukemia must follow certain protocols, mainly related to white and red blood cells or platelet counts, and the presence of the dentist in a multidisciplinary team is required for the health care of such patients. Lukemic patients require permanent dental control. It can mitigate pathological processes in the oral cavity related to the disease and its treatment. Such an approach will help prevent local complications also affecting patients' general condition.
\end{abstract}

Keywords: mucositis, oral mucosa, gingival hyperplasia, chemotherapy, leukemia

\section{Introduction}

Leukemias constitute a group of neoplastic diseases originating from the hematopoietic system, where all morphotic elements of blood are formed. Leukemias occur more frequently in men than in women $(3: 2)$, and particular types reveal the highest prevalence in different age ranges [1-3]. The etiopathogenesis of leukemias has not been fully understood. On the basis

*e-mail: mptasiewicz@vp.pl of experimental and clinical studies, it has been stated that changes in the genes caused by different types of viruses may play a crucial role in the neoplastic transformation. These are mainly retroviruses, and less frequently DNA viruses can lead to mutation as early as in the foetal life or soon after birth. Genetic information within viruses is embedded into the host's genome. It can remain in the latent phase and be passed on to daughter cells. This factor determines whether the disease remains in its latent phase or neoplastic transformation occurs [4].

Apart from the virus activity in leukemias pathogenesis, an individual predisposition is also 
considered. The changes in particular functions of normal genes may lead to the development of neoplastic diseases of the hematopoietic system. These genes are called proto-oncogenes or cellular oncogenes and their function is to encode the proteins responsible for cell proliferation and maturation. In neoplastic diseases developing in people, oncogenes may be activated as a result of translocations, point mutations or amplifications. Another group of genes, while functioning properly, takes part in the negative control of cell proliferation. These are the so-called tumour suppressor genes, whose deactivation as a result of mutation or deletion, for example, may be the cause of uncontrolled cell proliferation. The improper expression of these genes may also lead to the development of neoplasms $[5,6]$. The mechanism underlying the increased number of cancer cells is complex. Stem cells reveal the impaired ability of differentiation and maturation and they are insensitive to feedback factors inhibiting their excessive differentiation. As a result, cancer cells are formed and the defect affects the whole population, or normal cells are present alongside cancer cells, which pass from the bone marrow to the blood, which is probably related to the disorders of the formation of receptors in their membrane and which inhibit the passage of immature cells into the blood.

The increase in the number of immature cells is also the result of their survival time in relation to normal cells. Likewise, many external factors (socalled cofactors) may inhibit anticancer control in the cells. They include chemical agents, ionizing radiation, environmental factors, and infections. These factors may directly affect the cells that cause and undergo neoplastic transformation [7-11]. Laboratory tests are crucial in the diagnosis of leukemia. In the course of hematological treatment antiemetics, antidepressants, neuroleptics, sedatives and $\beta$ adrenergic receptor blockers are also administered. These drugs cause the decrease of saliva secretion and the change in its composition, which leads to the decrease of $\operatorname{IgA}$, lactoferrin and lysozyme, and increases the activity of peroxidase with the concurrent decrease of thiocyanates. The essential reason for xerostomia in leukemic patients is also the stress resulting from the disease and treatment. The qualitative and quantitative changes in the saliva during chemotherapy significantly influence the development of oral mucositis [12].

The degree of severity of inflammatory changes in the oral mucosa and periodontium may be of different progression. It is defined by a five-grade scale according to WHO [13]:

1- No changes.

2- Redness and considerable mucosal oedema, discomfort in the oral cavity.

3- Redness, oedema, erosions in the epithelium of the oral mucosa, the patient is still able to ingest solid food.

4- Oral mucositis, ulcerations, the patient is only able to drink, they are not able to ingest solid food.
5- Extensive inflammatory and necrotic changes in the oral mucosa, including the lips, throat and oesophagus, the patient is not able to ingest any solid food or drink and requires parenteral nutrition.

The National Cancer Institute has developed the following simplified scale [14]:

1- No changes.

2- Painless ulcerations and inflammation.

3- Painful redness and accompanying ulcerations.

4- Painful redness and ulcerations in conjunction with dysphagia.

5- Extensive ulcerations with possible intubation.

The ability to swallow is also assessed according to a five-grade scale:

1- No dysphagia.

2- Pain on swallowing; however, ingestion of solid food is possible.

3- Semi-solid or liquid diet.

4- The patient requires additional parenteral nutrition.

5- The patient is not able to swallow.

The mucous membrane of the oral cavity is where the first manifestations of pathological symptoms frequently take place. Bleeding of the gums is a frequent symptom in leukemic patients and it is the first sign in the oral cavity. The other most frequently occurring symptoms may be: a painful and burning tongue, erythematous atrophic changes, petechiae, swollen gums, gingival hyperplasia, type-specific and inflammatory infiltrations, oral mucosa erosions, ulcerations and necrotic changes [15].

\section{Materials and Method}

The present study aimed to identify abnormalities of the oral cavity that occur during chemotherapy. The oral health in leukemic patients was assessed during one cycle of haematological treatment. The state of the oral mucosa was assessed and evaluated depending on the number of white and red blood cells, platelets count and the level of hemoglobin. Disease advancement and response to treatment were monitored in patients based on selected hematological parameters. According to the direction of changes, i.e., a decrease or increase in individual elements of blood morphology, an attempt was made to determine whether there is a relationship between the clinical picture of the oral mucosa and the response to the treatment used in patients with leukemia.

\section{Sampling}

The study included 102 patients treated because of primary diagnosed leukemia. The patients were hospitalized at the Clinic of Hemato-Oncology and Bone Marrow Transplantation of the Independent Public Clinical Hospital No. 1 in Lublin. The study included 51 women $(50,00 \%)$ and 51 men (50, 00\%) aged 22 to $72(54.07 \pm 10.33)$. All clinical data, laboratory 
test results, information about the diagnosis, applied treatment and its course were obtained from hospital records. The study was carried out according to the Helsinki Declaration. All patients gave informed consent to participate in the study.

The first study, in which oral health state was assessed, was carried out before the next phase of treatment and before the next cycle of chemotherapy, whereas the following study (control study) was conducted after the chemotherapy cycle had been completed.

In 55 patients acute myelogenous leukemia was diagnosed (53.92\%), in 17 patients chronic lymphocytic leukemia (16.67\%), in 16 acute lymphoblastic leukemia $(15.69 \%)$ and in $10(9.80 \%)$ chronic myelogenous leukemia. The acute promyelocyticleukemia was diagnosed in 3 patients $(2.94 \%)$ and chronic hairy cell leukemia in 1 patient $(0.98 \%)$. The simplified division of leukemia into its chronic and the acute forms was used for statistical analysis.

In the course of hematological treatment the patients had their blood parameters monitored. All blood samples were collected at the request of a hematologist to assess and measure the course of leukemia. Patients' blood samples were taken by the clinic staff, and the blood parameters analysis came from the hospital laboratory. The white and red blood cell counts, the platelets count and the level of hemoglobin were evaluated. It was assumed that the parameters evaluated by a hematologist in the leukemic patients constitute research material for the present thesis. Relevant findings and statistical analysis were based strictly on parameters describing the oral state.

\section{Oral State Assessment}

Clinical examination involved anamnesis and physical examination. Anamnesis included age, sex, medical history and related general complaints within the oral cavity and oral hygiene habits. In the physical examination, attention was drawn to general complaints in a patient such as increased temperature, skin pallor and petechiae. Data were collected in the dental office of the Clinic of Hemato-Oncology and Bone Marrow Transplantation of the Independent Public Clinical Hospital No. 1 in Lublin and in patients' beds. Evaluations were performed using artificial lighting. A detailed examination concerned the state of the oral mucosa. A basic dental diagnostic kit and calibrated periodontal probe were used. During the oral examination, attention was drawn to spontaneous gingival bleeding or on gentle probing, loose teeth and the presence of supragingival and subgingival dental deposits. Periodontal pockets and their depth were evaluated with the use of a calibrated periodontal probe. The measurement of clinical attachment loss from the cementoenamel junction to the pocket depth provides objective results in the case of gingival hypertrophy or recession. During the oral mucosa examination, hydration, colour, and the presence of pathological changes, for example, petechial haemorrhages, hypertrophies, erosions and ulcerations were evaluated. Lips, the oral vestibule, the cheeks, the floor of the mouth, the tongue and the palate were evaluated.

\section{Statistical Analysis}

The obtained study results were submitted for statistical analysis. The calculation for quantitative traits included: range of values (min., max), arithmetic mean (M), and standard deviation (SD). Differences between the compared groups for quantitative traits were verified with tests (depending on the stated distribution): for dependent variables - Students'- $t$, Wilcoxon, for independent variables - Student's -t, Mann-Whitney U test. The differences in the prevalence of the analyzed traits between particular groups were tested with $\chi^{2}$ test (Fisher's $\chi^{2}$ ). The study adopted a 5\% risk of error, therefore statistically significant differences were those of $p<0.05$. All the calculations were carried out with the Statistica 12 software package (StatSoft, Tulsa, OK, USA).

\section{Results and Discussion}

The incidence and type of pathological changes in the oral mucosa before chemotherapy were evaluated. The applied treatment of leukemia did not significantly differentiate the condition of the mucous membrane of the oral cavity (Table 1).

After chemotherapy, oral lesions occurred statistically significantly more often within the oral mucosa of patients who had lower numbers of white blood cells $(\mathrm{WBC})(\mathrm{p}<0.05)$. No such correlation was stated before the therapy (Table 2).

A red blood cell (RBC) count was reflected in the frequency of incidence of oral lesions in patients after chemotherapy $(p<0.01)$. Most frequently abnormalities within the oral mucosa were stated in people who had lower numbers of erythrocytes after hematological treatment (Table 3).

Statistically significantly more changes on the oral mucosa occurred in patients who had a decrease in haemoglobin (HGB) before as well as after chemotherapy (Table 4).

The categorized number of platelets (PLT) did not statistically significantly differentiate lesions within the oral mucosa of the patients (Table 5).

A dental surgeon can be the first doctor who will see the patient with the impaired hematopoietic and lymphatic systems. It is crucial to evaluate oral changes in a patient who is already in the course of treatment of hematologic disease. Laboratory tests are important in the diagnosis of leukemia. In the acute myelogenous leukemia, complete blood count most frequently reveals leukocytosis with the presence of atypical forms, 
Table 1 . Chemotherapy cycle versus state of the oral mucosa.

\begin{tabular}{|c|c|c|c|c|c|c|}
\hline \multirow{2}{*}{\multicolumn{2}{|c|}{$\mathrm{n}$}} & \multicolumn{2}{c|}{ Before treatment } & \multicolumn{2}{c|}{ After treatment } & $\mathrm{p}$ \\
\cline { 3 - 6 } & & $\%$ & $\mathrm{n}$ & $\%$ & \\
\hline 0 & Normal oral mucosa & 40 & 39.22 & 39 & 38.23 \\
\hline I & Gingival hyperplasia & 16 & 15.69 & 19 & 18.63 \\
\hline II & Hyperaemia / petechiae & 8 & 7.84 & 11 & 10.78 & 0.4220 \\
\hline III & Mucositis & 11 & 10.78 & 11 & 10.78 & 7.84 \\
\hline IV & Candidiasis & 9 & 8.82 & 8 & 14.05 \\
\hline V & Ulcerations & 18 & 17.65 & 14 & \\
\hline
\end{tabular}

Table 2. Categorized number of leukocytes (WBC) and pathological changes within the oral mucosa.

\begin{tabular}{|c|c|c|c|c|c|c|}
\hline & & \multicolumn{4}{|c|}{ WBC } & \multirow{3}{*}{$\mathrm{p}$} \\
\hline & & \multicolumn{2}{|c|}{$\downarrow$} & \multicolumn{2}{|c|}{$\uparrow$} & \\
\hline & & $\mathrm{n}$ & $\%$ & $\mathrm{n}$ & $\%$ & \\
\hline \multirow{2}{*}{ Before chemotherapy } & yes & 37 & 61.67 & 25 & 59.52 & \multirow{2}{*}{0.4941} \\
\hline & no & 23 & 38.33 & 17 & 40.48 & \\
\hline \multirow{2}{*}{ After chemotherapy } & yes & 42 & 70.00 & 21 & 50.00 & \multirow{2}{*}{$<0.05$} \\
\hline & no & 18 & 30.00 & 21 & 50.00 & \\
\hline
\end{tabular}

yes - occurrence of pathological changes within the oral mucosa

no - oral mucosa without pathological changes

$\downarrow$ decrease in the number of white blood cells

$\uparrow$ increase in the number of white blood cells

Table 3. Categorized number of erythrocytes $(\mathrm{RBC})$ and pathological changes within the oral mucosa.

\begin{tabular}{|c|c|c|c|c|c|c|}
\hline & & \multicolumn{4}{|c|}{$\mathrm{RBC}$} & \multirow{3}{*}{$\mathrm{p}$} \\
\hline & & \multicolumn{2}{|c|}{$\downarrow$} & \multicolumn{2}{|c|}{$\uparrow$} & \\
\hline & & $\mathrm{n}$ & $\%$ & $\mathrm{n}$ & $\%$ & \\
\hline \multirow{2}{*}{ Before chemotherapy } & yes & 50 & 65.79 & 12 & 46.15 & \multirow{2}{*}{0.0629} \\
\hline & no & 26 & 34.21 & 14 & 53.85 & \\
\hline \multirow{2}{*}{ After chemotherapy } & yes & 54 & 71.05 & 9 & 3.62 & \multirow{2}{*}{$<0.01$} \\
\hline & no & 22 & 28.95 & 17 & 65.38 & \\
\hline
\end{tabular}

yes - occurrence of pathological changes within the oral mucosa

no - oral mucosa without pathological changes

$\downarrow$ decrease in the number of red blood cells

$\uparrow$ increase in the number of red blood cells

whereas leucopoenia occurs less frequently. Blood smear contains blast cells, the percentage of which varies, depending on the stage of the disease and its character. Most frequently they resemble myeloblasts. Most often the basis of the diagnosis is cytological examination of the bone marrow, which reveals the prevalence of one type of blast cell with the coexisting regression of the erythrocyte and platelet system. Immunophenotyping is performed with the use of monoclonal antibodies. They may be decisive in the case where the first test does not lead to the final diagnosis. The test evaluates the presence of particular antigens, which indicates that abnormal cells are a part of the bone marrow cell line [16-18]. Cytogenetic studies allow us to define a risk group of the disease and they are also the basis for identifying the type of leukemia with the defined genetic defects. However, the tests are practically limited because waiting time for the results lasts a few days. Therefore, molecular studies are helpful in many cases. They are of importance in 
Table 4. Categorized hemoglobin value (HGB) and pathological changes within the oral mucosa.

\begin{tabular}{|c|c|c|c|c|c|c|}
\hline & & \multicolumn{4}{|c|}{ HGB } & \multirow{3}{*}{$\mathrm{p}$} \\
\hline & & \multicolumn{2}{|c|}{$\downarrow$} & \multicolumn{2}{|c|}{$\uparrow$} & \\
\hline & & $\mathrm{n}$ & $\%$ & $\mathrm{n}$ & $\%$ & \\
\hline \multirow{2}{*}{ Before chemotherapy } & yes & 47 & 73.44 & 15 & 39.47 & \multirow{2}{*}{$<0.01$} \\
\hline & no & 17 & 26.56 & 23 & 60.53 & \\
\hline \multirow{2}{*}{ After chemotherapy } & yes & 45 & 70.31 & 18 & 47.37 & \multirow{2}{*}{$<0.05$} \\
\hline & no & 19 & 29.69 & 20 & 52.63 & \\
\hline
\end{tabular}

yes - occurrence of pathological changes within the oral mucosa no - oral mucosa without pathological changes

$\downarrow$ decrease in the hemoglobin value

$\uparrow$ increase in the hemoglobin value

Table 5. Categorized number of platelets (PLT) and pathological changes within the oral mucosa.

\begin{tabular}{|c|c|c|c|c|c|c|}
\hline & & \multicolumn{4}{|c|}{ PLT } & \multirow{3}{*}{$\mathrm{p}$} \\
\hline & & \multicolumn{2}{|c|}{$\downarrow$} & \multicolumn{2}{|c|}{$\uparrow$} & \\
\hline & & $\mathrm{n}$ & $\%$ & $\mathrm{n}$ & $\%$ & \\
\hline \multirow{2}{*}{ Before chemotherapy } & yes & 46 & 61.33 & 16 & 59.26 & \multirow{2}{*}{0.5130} \\
\hline & no & 29 & 38.67 & 11 & 40.74 & \\
\hline \multirow{2}{*}{ After chemotherapy } & yes & 48 & 64.00 & 15 & 55.56 & \multirow{2}{*}{0.2916} \\
\hline & no & 27 & 36.00 & 12 & 44.44 & \\
\hline
\end{tabular}

yes - occurrence of pathological changes within the oral mucosa no - oral mucosa without pathological changes

$\downarrow$ decrease in the number of platelets

$\uparrow$ increase in the number of platelets

the diagnosis of minimally differentiated leukemias and help to evaluate changes in chromosomes and genes.

The histopathological study of the bone section in necessary to assess bone marrow stromal cells, whereas in the case of an inability to perform aspiration biopsy it can be the basis for making a diagnosis. Immunological studies are also performed as well as the test of haemostasis.

In the case of acute leukemias, the treatment can be divided into three phases: induction therapy, consolidation therapy and maintenance therapy [19, 20]. The first phase aims at a normalization of blood test results by the reduction of cancer cells so that the body can control the remaining number of abnormal cells. For this purpose polychemotherapy, in which at least two drugs are administered, is applied. It acts on the different phases of a cell cycle and thus the efficacy of treatment is increased. The therapy consists of the repetition of 5-7-day courses with intervals and leads to gradual destruction of cancer cells which had been insensitive to drugs in the previous cycle. The intervals also allow us to decrease the side-effects of cytostatics and restore proper hematopoiesis. A few days of intensive polychemotherapies leads not only to the destruction of cancer cells but also to the symptoms of bone marrow aplasia. The number of leukocytes and platelets decreases most frequently up to the 14th day of treatment and then blood cells regenerate and remission can occur. The next phase is a consolidation therapy that is maintenance of the obtained remission. Cancer cells that had been resistant to the drugs or are found in the places less accessible for cytostatics, like for example the central nervous system, are destroyed. The consolidation therapy is meant to prevent proliferation of cancer cells, though it can only be started after the full remission in the first two phases has been obtained. In addition, the supportive treatment is applied, which includes the prevention of infection - the treatment of infection with antibiotics, antiviral and antifungal drugs, and the treatment of anaemia and haemorrhagic diathesis. Proper nutrition is also essential, parenteral nutrition if necessary and in some cases also psychotherapy [21].

In the treatment of chronic lymphocytic leukemias it should be determined whether the patient requires immediate therapy or it can be postponed until the progression period. The therapy should be started when advanced clinical symptoms occur such as weight loss, fever, weakness or hematopoietic failure. The first drug that is used is chlorambucil, most frequently 
administered in a 5-7-day course of treatment every month or daily for 4-8 weeks. $60-90 \%$ of patients respond to the therapy, but the percentage of the total remission is small. Patients resistant to the initial therapy or with a relapse within 12 months are qualified for the treatment with purine nucleoside analogues if they had not been administered earlier. In patients with a relapse after one year, the previous treatment regimen can be used. In the case of total resistance to the treatment, palliative therapy should be considered.

In the case of chronic myelogenous leukemia, the aim of the treatment is to achieve full recovery or the longest possible survival time. At present, the only method that gives a chance of a complete recovery is allogeneic bone marrow transplant. In turn, pharmaceuticals that give a chance to achieve remission are interferon $\alpha$ and only recently used tyrosine kinase [22-24].

The mucous membrane is the place of the first manifestations of pathological symptoms caused by leukemia. Our results are in accordance with other studies $[11,19]$ about the discomfort related to the onset of oral cavity lesions, as most commonly observed in the initial period of oncological treatment. Bleeding of the gums is the first sign in the oral cavity in $17.7 \%$ and $4.4 \%$ patients with acute and chronic leukemia respectively. The other most frequently occurring symptoms may be swollen gums as well as gingival hyperplasia. Approximately $40 \%$ of cancer patients subjected to chemotherapeutic treatment exhibit oral complications resulting from stomatotoxicity with the common onset of inflammation and ulceration of the oral mucosa (mucositis), which clinically manifests in an edematous, erythematous and friable form, resulting in pain, discomfort, dysphagia, and systemic weakness being the most important oral complication resulting from antineoplastic chemotherapy. As observed in this study, previous studies have confirmed that in the examined patients, ulcerations and gingival hyperplasia were most frequently observed [25].

Gingival hyperplasia begins with interdental papilla and then spreads to marginal and attached gingiva. Tissue oedema is most frequently caused by leukocyte infiltration. Gingivae in leukemia are usually red in colour, spongy and have a tendency to pull back from the tooth surface. In the course of the disease they become purple, and fine granularities on their surface get smooth. Some patients may feel pain resulting from infiltration of the dental pulp and osseous tissue by cancer cells $[26,27]$. Despite the fact that local irritants may be predisposed to and intensify gingival response in leukemia, they are not essential for the development of changes in the oral cavity. In the majority of patients there are changes within periodontium and the oral mucosa after application of the systemic treatment in the course of leukemias, which usually involve radiotherapy and chemotherapy with cytostatics (methotrexate, cyclophosphamide, adriamycin, bleomycin) or the immunosuppressive treatment (cyclosporine A, imuran). The conducted treatment may cause clinical changes within the gingiva, frequently difficult to differentiate from the original disease or overlap its picture. Chemotherapy induces ulcerations and necrotic foci, fusospirillary gingivitis and is the cause of the secondary bacterial and viral super infections, e.g., in the form of labial herpes or angular cheilitis and fungal infections. Painful changes within the oral mucosa make it difficult for the patients to eat and drink, which leads to the quick loss of body weight. Our results are in accordance to other studies about the discomfort related to the onset of oral cavity lesions was most commonly observed in the initial period of oncological treatment [28-30].

The causes of the oral mucositis during chemotherapy are complex and multilateral. Complications occur at the critical value of granulocytes below 1000/ml of blood. Antineoplastics and cytostatics cause granulocytopenia and inhibit regeneration of stratified squamous epithelium. They damage not only its superficial layers, but also basilar cells of oral mucosa and submucous membrane. They also impair regenerative capacity of tissue and decrease epithelial thickness. The latest studies indicate the presence of changes in vascular endothelium and in the connective tissue of the submucosal layer. There is thickening of vascular walls and the destruction of their muscle and elastic fibres. Chemotherapy leads to the release of free radicals, which in turn activate cytokines. The presence of inflammatory mediators contributes to apoptosis and tissue damage, which manifests itself in the oral cavity as ulceration $[31,32]$.

In the oral cavity of leukemic patients physiological bacterial flora is destroyed and it is colonized with bacterial strains found outside the oral cavity, e.g., Klebsiella, Enterococcus foecalisor, and Pseudomonas aeruginosa. The duration of inflammation in the oral mucosa in patients after chemotherapy is 8 to 11 days on average, and depends on the rate of the bone marrow regeneration. Fungal superinfections are usually caused by Candida albicans and Candida tropicalis. They may be the reason for local complaints like pain, burning sensation, and taste disorders, or can cause generalized candidiasis. Lymphopenia and neutropenia occur after cytostatics, which cause myelosuppression and immunosuppression. Thus, druginduced granulocytopenia or agranulocytosis are the causes of severe immunosuppression and may lead to life-threatening infections [33, 34].

Diagnostic and therapeutic difficulties of the oral changes are additionally caused by the exacerbation or remission of the underlying disease. Maintaining proper oral hygiene by the patient may also be more difficult because of pain, intense bleeding or ulcerations frequently present after chemotherapy. A thorough mouth cleaning and the use of antiseptic mouthwashes are essential to reduce the symptoms of disease severity and side effects of the therapy. The treatment of mucositis should lead to the reduction of 
pain, sensation of dryness in the mouth and promote the healing of necrotic changes. The conducted clinical observations show that saliva substitutes, rinsing the mouth with sterile water, irrigations with sodium bicarbonate and the use of topical anaesthetics are effective. A number of centers conduct research on new medications and methods of mucositis treatment, e.g., the efficacy of cryotherapy was evaluated or keratinocyte growth factor (KGF) was used. The mechanism of KGF action consists of the stimulation of cells to reproduce by binding to the KGF receptor, which accelerates the healing process [35, 36]. Oral mucositis management was described in the guidelines of 2014 as multinational association of supportive care in the Cancer/International Society of Oral Oncology (MASCC/ISOO) and in the recommendations of the Polish Group of Specialists for Prophylaxis and the Treatment of Oral Complications, including doctors in oncological radiotherapy, clinical oncology, palliative medicine, hematology, periodontology, maxillofacial surgery, dental prosthetics, clinical nutrition and oral medicine [ 37].

Before starting dental treatment, hematological consultation is necessary, both in leukemic patients and in people with abnormal blood cell counts who are suspected of having the disease. Oral mucosa, teeth and periodontium should be thoroughly examined before chemotherapy in order to detect possible infection foci. Sometimes a delay in the planned treatment should be considered if there are active infection foci in the oral cavity, whereas in the case of asymptomatic periapical changes a continuation of dental treatment is possible after chemotherapy (although in such a case the patient should have antibiotic prophylaxis during myelosuppression). It is recommended to remove local irritating agents such as tartar, sharp edges of fillings or prosthetic restorations or rough tooth surfaces. When planning any surgical procedures such as tooth extractions, periodontal procedures or dental implants, patients' needs should be met as well as the prognosis and the anticipated survival time. Surgical treatment is recommended only in emergency cases and it sometimes has to be preceded with a blood transfusion because of anaemia or thrombocytopenia [38]. The dental surgeon should consider the risk of complications in patients undergoing long-term treatment with corticosteroids who have increased risk of infection and waterelectrolyte imbalance, as well as impaired healing. If a patient's condition is rapidly deteriorating and immediate antibiotic therapy is necessary, antibiotics with a wide spectrum of activity are administered intravenously.

In patients before the scheduled surgical procedures, blood cell and platelet counts are performed. A decrease in platelet count below $80000 / \mathrm{ml}$ may be a contraindication to the scheduled procedure. In the case of prolonged bleeding after surgery, local treatment should be started, or in more severe cases a general one. Conservative and prosthetic treatment should be based on the form and phase of the disease as well as prognosis. More favourable treatment should not be replaced by temporary fillings or partial dentures only because of leukemia diagnosis if there is a chance to restore the missing teeth, which is more comfortable for the patient [39].

Periodontal treatment of leukemic patients also requires proper management. In people who have developed periodontal disease before hematologic diagnosis, the treatment of periodontal symptoms should be undertaken in order to prevent their exacerbation. In the course of hematological treatment there is frequently an exacerbation of previously existing periodontal disease, which leads to local or systemic complications. A two-week healing period is recommended after all oral surgery procedures before the scheduled chemotherapy. It was stated that in the leukemic patients who were submitted to periodontal treatment (scaling) before chemotherapy, the percentage of the infection foci originating from the oral cavity was considerably lower than in people who did not have surgical procedures performed $(25 \%$ and $77 \%$ respectively). In patients with neutropenia treated for periodontal diseases, metronidazole, frequently administered in conjunction with antibiotics, has proven to be effective. It is administered generally as well as being applied topically [40, 41].

The limitations of the study were the general poor health of patients, improper oral hygiene, decreased immunity and systemic infections. There is not much information in the literature on the condition of the oral mucosa in patients before and after chemotherapy depending on hematological parameters. This issue requires further research in order to find the best method of treatment. The studies examining periodontal health and oral hygiene of patients with leukemia are rare, and until now data about the oral health situation of adult patients is insufficient [42, 43]. Oral manifestations and initial symptoms are often important in the early detection of leukemia. In approximately $25 \%$ of patients with acute myelogenous leukemia (AML), dentists are involved in the diagnosis. Beside this, poor oral health is associated with a higher risk of systemic infections and complications in these patients. Accordingly, sufficient dental therapy before chemotherapy or stem cell transplantation can reduce the septicaemia rate and its fatal consequences. Current papers primarily describe case studies or retrospective studies with a focus on AML and are unable to illustrate the oral health situation of patients before and after therapy. Consequently, knowledge about the oral conditions of patients is insufficient and the need for treatment of diagnosed patients appears unclear. Data from the U.S. National Cancer Institute claims that some cancer centers encourage tooth brushing and flossing, while others indicate the interruption of brushing and flossing when blood components have dropped below specified limits (e.g., platelets $<30,000$ cells $/ \mathrm{mm}^{3}$ ). However, according to the institute itself, there is no evidence in 
the literature regarding the best approach. The centers providing strategy argue that the benefits of proper brushing and proper flossing outweigh the risks, because the interruption of the oral hygiene routine increases the risk of infection, and this could promote bleeding as well as increase the risk of local and systemic infection [44-47].

\section{Conclusions}

On the basis of the obtained study results the following conclusions were stated:

1) In the examined patients, ulcerations and gingival hyperplasia were most frequently observed. These are typical disorders of the oral mucosa that occur in leukemia.

2) Pathological changes within the oral mucosa were observed more often in patients after chemotherapy who had decreased immunity assessed on the basis of a white blood cell count.

3) The decrease in the number of red blood cells and hemoglobin predisposes to pathological changes within the oral mucosa in leukemia.

4) Lukaemic patients require permanent dental control, which can mitigate pathological processes in the oral cavity related to the disease and its treatment. Such an approach will help prevent local complications also affecting the patients' general condition.

\section{Conflicts of Interest}

The authors declare no conflicts of interest.

\section{References}

1. ZIMMERMANN C., MEURER M.I., GRANDO L.J., GONZAGA DEL MORAL J.A., DA SILVA RATH I.B., SCHAEFER TAVARES S. Dental Treatment in Patients with Leukemia. Journal of Oncology. 2015.

2. PADMINI C., BAI K.Y. Oral and Dental Considerations in Pediatric Leukemic Patient. ISRN Hematology. 2014.

3. LUPI S.M., RODRIGUEZ Y., BAENA A., CERVINO G., TODARO C., RIZZO S. Long-Term Effects of Acute Myeloid Leukemia Treatment on the Oral System in a Pediatric Patient. Open Dent J. 2018.

4. BRAZELTON J., LOUIS P., SULLIVAN J., PEKER D. Temporomandibular joint arthritis as an initial presentation of acute myeloid leukemia with myelodysplasia-related changes: a report of an unusual case. J Oral Maxillofac Surg. 72 (9), 1677, 2014

5. CECCARELLI G., PRESTA R., BENEDETTI L., CUSELLA DE ANGELIS M.G., LUPI S.M., RODRIGUEZ Y., BAENA R. Emerging Perspectives in Scaffold for Tissue Engineering in Oral Surgery. Stem Cells Int. 2017.

6. BELVER L., FERRANDO A. The genetics and mechanisms of $\mathrm{T}$ cell acute lymphoblastic leukaemia. Nat. Rev. Cancer. 16, 494, 2016.
7. GOUDARZI G., DARYANOOSH S.M., GODINI H., HOPKE P.K., SICARD P., DE MARCO A., RAD H.D., HARBIZADEH A., JAHEDI F., MOHAMMADI M.J., SAVARI J., SADEGHI S., KAABI Z., OMIDI KHANIABADI Y.O. Impact of middle eastern dust storms on human health. Atmospheric pollution research. 8, 606, 2017.

8. CHEN Y., ZHANG J., MA Q., SUN C., HA S., ZHANG F. Human health risk assessment and source diagnosis of polycyclic aromatic hydrocarbons (PAHs) in the corn and agricultural soils along main roadside in Changchun, China. Hum Ecol Risk Assess 22, 706, 2016.

9. GOUDARZI G., GERAVANDI S., ALAVI N., IDANI E., SALMANZADEH S., YARI A.R., JAMSHIDI F., MOHAMMADI M.J., RANJBARZADEH A., ALAMDARI F.A., DARABI F. Association between cancer risk and polycyclic aromatic hydrocarbons' exposure in the ambient air of Ahvaz, southwest of Iran. International journal of biometeorology. 62 (8), 1461, 2018.

10. MOHAMMADI M.J., YARI A.R., SAGHAZADEH M., SOBHANARDAKANI S., GERAVANDI S., AFKAR A., SALEHI S.Z., VALIPOUR A., BIGLARI H., HOSSEINI S.A., RASTEGARIMEHR B. A health risk assessment of heavy metals in people consuming Sohan in Qom, Iran. Toxin Reviews. 37 (4), 278, 2018.

11. SOJKA M., SIEPAK M., JASKUŁA J., WICHERDYSARZ J. Heavy Metal Transport in a River-Reservoir System: a Case Study from Central Poland Pol. J. Environ. Stud. 27 (4), 1725, 2018.

12. LITTLE J.W., FALACE D.A., MILLER C.S., RHODUS N.L. Disorders of white blood cells in Dental Management of the Medically Compromised Patient. 373, 2007.

13. SONIS S.T. The pathobiology of mucositis. Nat. Rev. Cancer 4, 277, 2004.

14. NAPENAS J.J., BRENNAN M.T., BAHRANI-MOUGOT F.K., FOX P.C., LOCKHART P.B. Relationship between mucositis and changes in microflora during cancer chemotherapy. Oral Surg. Oral Med. Oral Pathol. Oral Radiol. Endod. 103, 48, 2007.

15. PARISI E., DRAZININ J., STOOPLER E., SCHUSTER S.J., PORTER D., SCOLLECITO T.P. Acute myelogenous leukemia: Advances and limitations of treatment. Oral Surg. Oral Med. Oral Pathol. 93, 257, 2002.

16. LOUDONA J.A., COLEMANB H.J., ALLENC C.M., SCHIFTER M., Ng T., AL-HORANI G. Rare oral manifestation of chronic myelogenous leukemia and its targeted therapy: A case report and literature review. Univers J Med. Dent. 1 (7), 79, 2012

17. DMOSZYŃSKA A., ROBAK T., Hus I. Podstawy hematologii (Basics of hematology). Wydawnictwo Czelej 2015, Lublin [In Polish].

18. KHALED S., AL MALKI M., MARCUCCI G. Acute myeloid leukemia: biologic, prognostic, and therapeutic insights. Oncology (Williston Park), 30 (4), 318, 2016.

19. MATHUR V.P., DHILLON J.K., KALRA G. Oral health in children with leukemia. Indian J Palliat Care. 18 (1), 12, 2012.

20. National Comprehensive Cancer Network. NCCN Practice Guidelines in Oncology: Acute Lymphoblastic Leukemia. $1,2018$.

21. DOUMBIA M., UWINGABIYE J., BISSAN A., RACHID R., BENKIRANE S., MASRAR A. Epidemiological, clinical, cytologic and immunophenotypic aspects of acute leukemia in children: The experience at the hematology laboratory of IBN SINA University Hospital 
Center. Pan. Afr. Med. J. 23, 258, 2016. doi: 10.11604/ pamj.2016.23.258.8396.

22. TERWILLIGER T, ABDUL-HAY M. Acute lymphoblastic leukemia: A comprehensive review and 2017 update. Blood Cancer J. 7 (6), 577, 2017.

23. SUBRAMANIAN P., BABU K.L., NAGARATHNA J. Oral manifestations in acute lymphoblastic children under chemotherapy. J Clin. Pediatr Dent. 32 (4), 319, 2008.

24. SILVA B.A., SIQUEIRA C., CASTRO P., ARAÚJO S.S., VOLPATO L.E. Oral manifestations leading to the diagnosis of acute lymphoblastic leukemia in a young girl. J Indian Soc Pedod Prev Dent. 30 (2), 166, 2012.

25. GUZELDEMIR E., TOYGAR H.U., KOCER N.E., KIZILKILIC E. The periodontal management of a patient with acute myelomonocytic leukemia. Nobel Med. 8 (1), 110, 2012.

26. FRANCH A.M., ESTEVE C.G., PEREZ G.S. Oral manifestations and dental management of patient with leukocyte alterations. J Clin Exp Dent. 3 (1), 53, 2011.

27. KHERA P., ZIRWAS M.J., English JC 3rd. Diffuse gingival enlargement. J Am Acad Dermatol. 52 (3 Pt1), 491, 2005.

28. KAMIŃSKA-PIKIEWICZ K., CHAŁAS R., BACHANEK T. The condition of oral mucosa in the elderly (over 65 years) of Lublin. Curr. Iss. Pharm. Med. Sci. 30 (1), 39, 2017.

29. EPSTEIN J.B., STEVENSON-MOORE P. Periodontal disease and periodontal management in patients with cancer. Oral Oncology. 37, 613, 2001.

30. NASIŁOWSKA-ADAMSKA B.: Profilaktyka i leczenie zaburzeń przewodu pokarmowego towarzyszących chemioterapii i radioterapii [Prevention and treatment of gastrointestinal disorders accompanying chemotherapy and radiotherapy]. Hematologia.; 2 (2), 149, 2011 [In Polish].

31. POTTING C.M., UITTERHOEVE R., OPREIMER W.S., VAN ACHTERBERG T. The effectiveness of commonly used mouthwashes for the prevention of chemotherapyinduced oral mucositis: a systemic review. Eur J. Cancer Care. 15 (5), 431, 2006.

32. WYSOCKI W.M., MAŁECKI K.: Zapalenia błony śluzowej związane $\mathrm{z}$ radioterapią $\mathrm{i}$ chemioterapią. Podsumowanie wytycznych. Multinational Association of Supportive Care in Cancer/International Society of Oral Oncology (MASCC/ISOO) (2014 r.). [Mucositis associated with radiotherapy and chemotherapy. Summary of the guidelines of The Multinational Association of Supportive Care in Cancer/International Society of Oral Oncology] Cancer. 120, 1453, 2014 [In Polish].

33. DEMIRER S., OZDEMIR H., SENCAN M., MARAKOGLU I. Gingival Hyperplasia as an Early Diagnostic Oral Manifestation in Acute Monocytic. Leukemia: A Case Report. Eur J Dent. 4 (2), 111, 2007.

34. PETERSOM D.E. New strategies for management of oral mucositis in cancer patients. J. Support Oncol 4, 2, Suppl 1, 9, 2016.
35. WU J., FANTASIA J.E., KAPLAN R. Oral manifestations of acute myelomonocytic leukemia: a case report and review of the classification of leukemias. J Periodontol. 73 (6), 664, 2002.

36. DOMBRET H., GARDIN C. An update of current treatments for adult acute myeloid leukemia. Blood. 127 (1), 2016.

37. VELTEN D.B., ZANDONADE E., BARROS M.H.M. Prevalence of oral manifestations in children and adolescents with cancer submitted to chemotherapy. BMC Oral Health. 17, 3, 2017.

38. ALLAREDDY V., PRAKASAM S., ALLAREDDY V., MARTINEZ-SCHLURMANN N.I., RAMPA S., NALLIAH R.P., ESWARAN S.V., ELANGOVAN S. Poor oral health linked with increased risk of infectious complications in adults with leukemia. J Mass Dent Soc 64 (3), 38, 2015.

39. APPELBAUM F.R. CHAPTER 98: Acute Leukemias in Adults. In: NIEDERHUBER JE, ARMITAGE JO, DORSHOW JH, KASTAN MB, TEPPER JE, eds. Abeloff's Clinical Oncology. $5^{\text {th }}$ ed. Philadelphia, Pa. Elsevier: 2014.

40. CARREGA G., CASTAGNOLA E., CANESSA A., ARGENTA P., HAUPT R., DINI G., GARAVENTA A. Herpes simplex virus and oral mucositis in children with cancer. Support Care Cancer 2, 266, 2004.

41. DELIVERSKA E.G., KRASTEVA A. Oral signs of leukemia and dental management -literature data and case report. J of IMAB. 19 (4), 2013.

42. BUSJAN R, HASENKAMP J, SCHMALZ G, HAAK R, TRÜMPER L, ZIEBOLZ D. Oral health status in adult patients with newly diagnosed acute leukemia. Clin Oral Investig. 22 (1), 411, 2018.

43. DOUMBIA M., UWINGABIYE J., BISSAN A., RACHID R., BENKIRANE S., MASRAR A. Epidemiological, clinical, cytologic and immune phenotypic aspects of acute leukemia in children: The experience at the hematology laboratory of IBN SINA University Hospital Center. Pan Afr. Med. J. 23, 258, 2016.

44. RAVIKUMAR R., MANOHAR R., LATHA S.M., SCOTT J.X. Gingival hypertrophy in a child: Expect the unexpected. Indian J. Dent. 7 (2), 112, 2016.

45. FRANCISCONI C.F., CALDAS R.J., OLIVEIRA MARTINS L.J., FISCHER RUBIRA C.M., DA SILVA SANTOS P.S. Leukemic oral manifestations and their management. Asian Pac J Cancer Prev. 17 (3), 911, 2016.

46. DE FELICE F., GRAPULIN L., MUSIO D., POMPONI J., DI FELICE C., IORI A.P., BERTAINA A., TOMBOLINI V. Treatment complications and long-term outcomes of total body irradiation in patients with acute lymphoblastic leukemia: A single institute experience. Anticancer Res. 36 (9), 4859, 2016.

47. MATHUR V.P., DHILLON J.K., KALRA G. Oral health in children with leukemia. Indian J Palliat Care. 18 (1), 12, 2012. 
